\title{
Development of apparel designs using Mishing textile motifs
}

\section{Lizamoni Chungkrang}

Received: 10.01.2020; Revised: 21.03.2020; Accepted: 06.05.2020

Author for Correspondence:

Lizamoni Chungkrang Department of Textiles and Apparel Designing, Faculty of Community Science, Assam Agricultural University, Jorhat (Assam) India

Email : kutumlucy@gmail.com
ABSTRACT : At present the trend is towards change in styles in clothes with more reliance on accessories for variety. A new fashion is almost always an evolution. So, an attempt was made to development of apparel designs using textile motifs of Mishing community through fabric painting, block printing and embroidery techniques. A set of twenty four numbers of apparels suitable for adolescents were designed and sketched by placing the chosen motifs. Out of twenty four, six designs of Palazzo, Fitted skirt and top, Kurti, Long gown, Stole, and Mekhela - Chadar were selected based on the results of the survey conducted. The selected motifs were prepared by using Coral Draw Software. The basic blocks were prepared and drafted based on the standardized body measurements. The constructed apparels were systematically evaluated by panel of judges and consumers from different fields of textiles with the help of a structured questionnaire. From the findings it can be concluded that it is possible to develop new and interesting designs from the Mishing traditional motifs to meet the excessive demands of contemporary designs in the fashion and apparel fields and also increase the variety of designs in the field of textiles.

KEY WORDS: Evolution, Traditional motifs, Fabric painting, Block printing, Embroidery, Coral Draw, Contemporary design

- HOW TO CITE THIS PAPER : Chungkrang, Lizamoni (2020). Development of apparel designs using Mishing textile motifs. Asian J. Home Sci., 15 (1) : 104-109, DOI: 10.15740/HAS/AJHS/15.1/104-109. Copyright@ 2020: Hind Agri-Horticultural Society. 